\title{
Análise e indexação da paisagem: o Arquivo Fotográfico llustrativo dos Trabalhos Geográficos de Campo do Instituto Brasileiro de Geografia e Estatística
}

\section{Landscape analysis and indexing: Arquivo \\ Fotográfico llustrativo dos Trabalhos \\ Geográficos de Campo from the Instituto \\ Brasileiro de Geografia e Estatística \\ (Brazilian Institute of Geography and Statistics)}

\author{
Vera Lucia Punzi Barcelos CAPONE' \\ Rosa Inês de Novais CORDEIRO²
}

\section{Resumo}

O propósito desta pesquisa é abordar a análise e a indexação de paisagens da vida rural tendo por referência o Arquivo Fotográfico llustrativo dos Trabalhos Geográficos de Campo, do Instituto Brasileiro de Geografia e Estatística, cujas fotografias foram produzidas pelos geógrafos agrários do então Conselho Nacional de Geografia, entre os anos de 1940 e 1960. Trata-se de uma pesquisa exploratória que aborda a informação geográfica no âmbito da Ciência da Informação voltada para a organização e a representação do conhecimento registrado no processo de transferência da informação. Partindo de estudos sobre a paisagem levantados na literatura de Geografia e conjugado com a bibliografia das áreas de Arquivologia, Biblioteconomia, Ciência da Informação e História, buscou-se identificar conceitos e categorias que subsidiaram a proposta de uma matriz para análise e indexação de fotografias de paisagens. Os conjuntos fotográficos selecionados do acervo para o experimento referem-se às regiões brasileiras Nordeste e Sul, de acordo com a primeira divisão oficial proposta pelo Conselho Nacional de Geografia em 1941.

Palavras-chave: Arquivo fotográfico. Fotografias. Instituto Brasileiro de Geografia e Estatística. Indexação de fotografias. Paisagens.

\footnotetext{
Abstract

The purpose of this research is to discuss the analysis and indexing of rural life landscapes using Arquivo Fotográfico llustrativo dos Trabalhos Geográficos de Campo from the Instituto Brasileiro de Geografia e Estatística as reference. The photographs were taken by agrarian geographers from the former Conselho Nacional de Geografia between the years 1940 and 1960. This is an exploratory

1 Instituto Brasileiro de Geografia e Estatística, Centro de Documentação e Disseminação de Informações. R. General Canabarro, 706, Maracanã, 20271-201, Rio de Janeiro, RJ, Brasil. Correspondência para/Correspondence to:V.L.P.B. CAPONE.E-mail:<caponevera@gmail.com>.

2 Universidade Federal Fluminense, Departamento de Ciência da Informação, Programa de Pós-Graduação em Ciência da Informação. Niterói, RJ, Brasil. Recebido em 18/11/2014, reapresentado em 15/1/2015 e aceito para publicação em 2/3/2015
} 
research that addresses the geographic information within information science, aimed at the organization and representation of recorded knowledge in the process of information transference. From studies on landscape in the Geography literature associated with studies in the fields of Archival Science, Library Science, Information Science and History, we sought to identify concepts and categories that supported the proposal of a pattern for analysis and indexing of landscape photography. The photographic sets selected for the experiment are related to the Northeast and Southern Brazilian regions, according to the first official division of the regions proposed by the ConseIho Nacional de Geografia in 1941.

Keywords: Photographic archive. Photographs. Instituto Brasileiro de Geografia e Estatística. Photograph indexing. Landscapes.

\section{Introdução}

Tendo em conta os pressupostos epistemológicos que regem o campo de conhecimento da Ciência da Informação, entre outros, seus processos de construção e processamento da informação para acesso e respectivo uso, o universo desta pesquisa aborda a informação (conhecimento) geográfica(o) no âmbito da Ciência da Informação, voltada para a organização e a representação do conhecimento registrado no processo de transferência da informação. Este artigo é resultado de pesquisa de mestrado concluída no Programa de Pós-Graduação em Ciência da Informação da Universidade Federal Fluminense em 2013.

As fotografias analisadas refletem imagens das características geográficas peculiares a cada região brasileira, expressas por paisagens da vida rural que constituem o Arquivo Fotográfico Ilustrativo dos Trabalhos Geográficos de Campo do Instituto Brasileiro de Geografia e Estatística (IBGE). Essas imagens foram produzidas por geógrafos agrários em expedições promovidas pelo Conselho Nacional de Geografia (CNG). O limite cronológico coberto pelo acervo abrange as décadas de 1940 a 1960 .

Assim, procurou-se entender os sentidos da paisagem e do espaço que rege a vida rural no contexto e demanda da época em que esses documentos foram produzidos, perguntando: como interrogar esses documentos? Que aspectos, categorias e pontos de acesso devem ser considerados para análise e indexação visando à recuperação dessas fotografias tendo em vista as demandas de usuários e a literatura das áreas de Geografia e da Ciência da Informação? Para responder essas indagações buscou-se, na literatura da área de Geografia, os estudos centrados na conceituação, descrição e explicação da paisagem, tendo sido de fundamental importância compreender o termo a partir da visão do geógra- fo, pois pode-se estabelecer parâmetros que auxiliaram a identificação das categorias e subcategorias elencadas na matriz proposta.

Na literatura da área da Ciência da Informação o presente trabalho pautou-se no domínio da análise, descrição e indexação de imagens para sua posterior recuperação. Tentando potencializar o uso do conteúdo desses documentos, tornou-se necessário ampliar os procedimentos metodológicos da análise indexadora através da abrangência das categorias e subcategorias que foram aplicadas na representação desses registros. De acordo com Cordeiro (2010), a amplitude dessas categorias pode ressaltar o domínio informativo na mediação entre o documento e o usuário do sistema de informação, seja ele real ou potencial. Outra questão que a autora acentua é a correspondência entre o propósito na indexação da imagem e o estabelecimento dos objetivos que se pretende alcançar, tendo sempre em vista as necessidades dos usuários. Atentando para essa questão, no presente estudo desenvolveu-se uma matriz conceitual das categorias e subcategorias que foram analisadas no conjunto fotográfico e, em especial, no exame das paisagens.

Em síntese, a questão de pesquisa debruçou-se sobre a representação da imagem fotográfica, procurando revelar quais categorias, conceitos e termos são úteis para descrevê-las e indexá-las, considerando a época em que foram geradas, o método de pesquisa dos geógrafos agrários, o sistema de informação atual e seus usuários. Assim, a fim de propor uma matriz para análise documentária da paisagem de natureza, identificou-se entre os anos de 1947 e 1968, na literatura da área de Geografia, em especial na Revista Brasileira de Geografia (RBG), os métodos de pesquisa dos geógrafos agrários do CNG no estudo da paisagem e sua compreensão acerca de seu conceito. Em concomitância, procedeu-se a revisão de literatura em periódicos nacionais e interna- 
cionais, abrangendo o período de 2006 a 2011, e em teses e dissertações nas áreas de Biblioteconomia, Arquivologia, Ciência da Informação e Geografia, dos anos de 2002 a 2012.

A partir dessa revisão, percebeu-se a recorrência dos termos "paisagem" "espaço", ideias-chave que determinaram o desenvolvimento da pesquisa. Com base nesses termos, estabeleceu-se o marco teórico-conceitual que norteia a fundamentação deste trabalho. Examinando os assuntos "paisagem"e "espaço", deparou-se com uma discussão profícua, que despontou apontamentos singulares analisados por Blanc-Pamard e Raison (1986) e pelo geógrafo Santos (2009).

Conforme Blanc-Pamard e Raison (1986), paisagem é um termo habitualmente utilizado no cotidiano, mas seu significado é polissêmico, sendo empregado por várias disciplinas tão vagas quanto variadas. A compreensão da paisagem é vista sob o olhar de diversas culturas e, de acordo com cada época, foi influenciada pelas artes, religião, filosofia, entre outros aspectos. Em direção a uma conceituação do termo, os autores acima citados apresentam a definição atribuída pela escola francesa, citando Bertrand (1972). Para o geógrafo francês, "paisagem é a combinação dinâmica de elementos físicos, biológicos e antrópicos" (p.2) configurando-se num sistema global, pois o autor descarta a ideia de uma simples junção de elementos geográficos, no qual não se considera as implicações da participação do homem. Já a construção do mesmo conceito pelo geógrafo Santos (2009), associa-se ao enfoque do espaço geográfico como um híbrido, pois o mesmo é um resultado inseparável de sistemas de obje-tos e de ações, daí sua tese propondo uma necessidade epistemológica na distinção entre paisagem e espaço:

Paisagem e espaço não são sinônimos. A paisagem é o conjunto de formas, que num dado momento, exprimem as heranças que representam as sucessivas relações localizadas entre homem e natureza. O espaço são essas formas mais a vida que as anima (Santos, 2009, p.103).

Santos (2009), analisando a paisagem pelo viés da temporalidade, a interpreta como transtemporal, pois une objetos reais passados e presentes, e uma construção transversal. Já o espaço assume construção horizontal, pois é sempre um presente, uma situação única criada em momentos históricos diferentes. Embora ambos os termos não sejam sinônimos, há uma relação de similaridade entre os dois, dado que coexistem num dado momento, sendo o espaço parte da paisagem.

Enser (2009), em ampla revisão de literatura, discorre sobre os desafios que norteiam a busca e a recuperação de imagens visuais de diversas naturezas. Em uma retrospectiva, aborda os impactos exercidos pela criação de novas tecnologias nesse campo de estudo e as dificuldades oferecidas no momento da indexação de assuntos de materiais iconográficos na tradução da imagem ao se fazer a transposição da percepção imagética.

Paralelamente, Raper (2011) discute a informação geográfica. Em artigo de revisão, o autor chama a atenção para o fato da mesma ser pouco explorada pela Ciência da Informação. Apesar disso, o assunto oferece um vasto campo para discussões, dado seu aspecto multidisciplinar, não se limitando apenas aos mapas, mas abrangendo também uma vasta gama de informações.

No campo da Ciência da Informação, no que tange à organização e representação do conhecimento, é oportuno mencionar a proximidade conceitual entre catalogação de assunto, indexação e análise documentária, sendo que os dois últimos termos são abordados neste trabalho. Conforme Guimarães (2009), no espaço conceitual ocupado pelo tratamento temático da informação discute-se a catalogação de assunto, a indexação e a análise documentária, as quais são estudadas a partir de três perspectivas teóricas, porém "apresentam efetiva complementaridade (inclusive histórica) [...], revelam denominações distintas para fenômenos semelhantes" (Guimarães, 2009, p.112).

Neste artigo, as expressões indexação e análise documentária são usadas como afins e incluem, em suas conceituações, as operações de "análise conceitual e tradução" do conteúdo do documento para a sua representação e recuperação no sistema. Essas operações são denominadas por Lancaster (2004, p.9) como as etapas da indexação. Soma-se a isso o uso do vocábulo "análise indexadora" (Cordeiro, 2000, p.77) o qual é empregado para caracterizar o resultado do trabalho realizado pelo profissional (indexador) decorrente das etapas citadas e 
que acaba, por exemplo, atribuindo termos aos documentos (fotografias).

\section{Procedimentos metodológicos}

Neste estudo, o referencial teórico foi obtido por meio do mapeamento da literatura do período de 2006 a 2012 e nos seguintes momentos: primeiro, considerouse a literatura nacional das áreas de Arquivologia, Biblioteconomia e Ciência da Informação, levando-se em conta artigos de periódicos, teses e dissertações, procurando examinar as principais tendências dos autores no que se refere à organização, análise e indexação de fotografias. Segundo, com base no estudo da literatura da área de Geografia, percebeu-se a recorrência dos termos "paisagem"e "espaço", ideias-chave que determinaram o desenvolvimento desta pesquisa.

Também, foi possível identificar os elementos que compõem a paisagem, suas formas naturais, modificadas e organizadas, bem como suas características intrínsecas. Tal concepção possibilitou levantar as principais categorias e subcategorias de análise que deveriam estar presentes na matriz a ser aplicada na averiguação documentária de fotografias para posterior recuperação. Isso se deu através de pontos de acesso que potencializam a recuperação pela perspectiva do usuário e sua contribuição para a construção da memória social desenrolada na vida rural.

Entre os modelos cognitivos de categorização, isto é, os modelos clássicos e de protótipo (Lima, 2010), adotou-se a ideia de categoria clássica. Esta foi conceituada por suas características "necessárias e suficientes" (Lima, 2010, p.113), pois na estrutura da matriz proposta as categorias e as subcategorias compartilham o mesmo grau de importância, não havendo distinção entre as mesmas.

Com a finalidade de dar corpo à proposta, foram elegidas duas regiões brasileiras, Sul e Nordeste, de acordo com a primeira divisão oficial proposta pelo CNG em 1941, por representarem diferentes aspectos regionais, espaciais e socioculturais que caracterizam essas regiões. Dentre esses conjuntos de fotografias foram selecionadas duas fotografias de cada estado, sendo eles: Maranhão,
Piauí, Ceará, Rio Grande do Norte, Paraíba, Pernambuco e Alagoas (Nordeste); São Paulo, Paraná, Santa Catarina e Rio Grande do Sul (Sul). O recorte das fotografias selecionadas teve por critério a representação da vida rural nessas duas regiões. Concluídas essas etapas, estabeleceu-se uma comparação com a descrição e a análise feitas anteriormente a esta pesquisa no Sistema Infobib do IBGE, com o propósito de identificar as lacunas que se apresentam mediante a nova proposta, considerando o atendimento aos usuários do sistema, bem como as categorias e as subcategorias aplicadas na análise dos dados.

\section{Produção de fotografias paisagísticas}

A Escola Clássica da Geografia, compreendendo os anos de 1930 a 1950, empregava como um dos métodos e procedimentos técnicos adotados por geógrafos agrários o "estudo da paisagem", como observa Alves (2009, p.6). O autor, que em artigos publicados nos periódicos Boletim Geográfico e RBG, editados pelo CNG, busca definição desses métodos a fim de resgatar a história do pensamento geográfico.

As estratégias científicas de pesquisa geográfica empregadas no trabalho dos geógrafos do CNG apoiavam-se em três pilares (Ruellan, 1943): o trabalho de gabinete, as análises em laboratório e os estudos feitos no terreno. O trabalho de gabinete consistia em pesquisas de arquivos e bibliotecas através da análise de documentos bibliográficos - gravuras, esboços, perfis de costas e fotografias com valor documentário -, auxiliando os geógrafos no estudo crítico que os conduzissem a comentários explicativos e, posteriormente, a conclusões. Esse tipo de trabalho proporcionava a possibilidade de verificação e comparação da descrição da paisagem. Mas era essencialmente no terreno que os geógrafos atuavam, procedendo à observação do conjunto paisagístico, cuja finalidade era descrever o próprio lugar para definir suas formas e relações. Essa atividade minuciosa, respaldada pelo método científico que delineava o pensamento geográfico, norteava o olhar que interpretaria com rigor a paisagem, produzindo, desse modo, pesquisas à luz da crítica científica que possibilitavam sua comprovação por meio das fotografias desse acervo (Ruellan, 1943). 


\section{O Arquivo Fotográfico Ilustrativo dos Trabalhos Geográficos de Campo do IBGE}

A atividade fotográfica no IBGE inicia-se em 1939, a partir da criação do Serviço de Geografia e Estatística Fisiográfica, criado pelo Decreto-Lei no 782 de 13 de outubro de 1938, e instalado em 15 de março de 1939 sob a dependência direta do CNG. O diretor desse serviço cria nessa repartição um centro de estudos que integra, como um de seus objetivos, as excursões ou trabalhos de campo para realização de estudos geográficos in loco: "De cada excursão é feita sempre que possível, uma documentação fotográfica, para a Filmo-Fototeca do Serviço" (Instituto Brasileiro de Geografia e Estatística, 1946, p.1173).

As pesquisas de campo empreendidas pelos geógrafos do IBGE têm seu ponto alto entre o início dos anos 1940 e final dos anos 1950, cabendo destacar que no começo dos anos 1950, imediatamente depois do pós-guerra, foram contratados três fotógrafos de origem húngara que se somavam às excursões. Eram eles Tibor Jablonski, Tomas Somlo e Stivan Faludi. Outros fotógrafos compunham o corpo técnico do CNG e, tal qual os húngaros, também acompanhavam os geógrafos durante as excursões, sendo eles Gilson Costa, Rubens Moreno Mazzola, Wilson de Souza Aranha, José Joaquim de Souza, Hermondino Chagas P. Santos Cruz e Nelson Sépula. Todos esses nomes figuram nas fotografias do acervo.

O cenário geográfico nacional no início dos anos 1960 experimenta uma nova dinâmica com a implantação de modernas máquinas dotadas de alta precisão adquiridas nos Estados Unidos. A não continuidade no desenvolvimento do acervo está relacionada à introdução desses novos aparelhos mais precisos empregados na aplicação do método de estudo dos geógrafos e cartógrafos, o qual exigia rigor na especialização da análise da paisagem, retratando os elementos que a compunham (Barros, 1964).

\section{Matriz para análise da paisagem}

É importante esclarecer que o acervo estudado recebe distintas demandas de uso. No que diz respeito aos usuários externos ao sistema as fotografias atendem a diversos propósitos, desde ilustrar livros didáticos de
Geografia a aparecer em pesquisas retrospectivas. Quanto aos internos, as imagens podem subsidiar as atividades do setor de Memória Institucional ou a Coordenação de Marketing no desenvolvimento de projetos institucionais para divulgação interna ou para o público em geral, cujo enfoque seja a recuperação da memória da instituição e da social.

A proposta de matriz apresentada abrange quatro categorias que se subdividem em 21 subcategorias, dispostas em quatro quadros. As subcategorias foram identificadas e conceituadas a partir do mapeamento da literatura das áreas de Arquivologia, Biblioteconomia, Ciência da Informação, História e, principalmente, Geografia, sendo:

Quadro 1 - Contexto Histórico de Produção; Quadro 2- Porção Aparente do Território; Quadro 3 - Configuração Territorial; Quadro 4 - Paisagem Típica (Valor Simbólico).

Vale notar que os estudos da paisagem elaborados pelos geógrafos agrários do IBGE nos anos pesquisados e publicados na Revista Brasileira de Geografia e nas obras Paisagens do Brasil e Geografia do Brasil: roteiro de uma viagem, permitiu eleger as subcategorias que abarcam os Quadros 2 e 3, bem como compreender o contexto histórico de produção das imagens que compõem o acervo (Quadro 1). A seguir, são dispostos na matriz os termos (palavras-chave) selecionados na literatura citada e que correspondem ao conjunto de fotografias selecionadas para o experimento.

Cabe esclarecer que optou-se por assinalar os vocábulos pelas siglas LC (uso de linguagem controlada), para aqueles com correspondência na lista de cabeçalhos de assuntos do catálogo de terminologia autorizada da

Quadro 1. Contexto histórico de produção.

\begin{tabular}{|c|c|c|}
\hline $\begin{array}{l}\text { Categoria e } \\
\text { subcategorias }\end{array}$ & Conceituação & $\begin{array}{l}\text { Cronologia e } \\
\text { Expedição }\end{array}$ \\
\hline $\begin{array}{l}\text { Contexto histórico } \\
\text { de produção }\end{array}$ & $\begin{array}{l}\text { Informações que iden- } \\
\text { tificam o contexto so- } \\
\text { cial em que as foto- } \\
\text { grafias foram produ- } \\
\text { zidas (Burke, 2004). }\end{array}$ & $\begin{array}{l}\text { Ano da expedição/ } \\
\text { estudo. Objetivo da } \\
\text { expedição/estudo. } \\
\text { Integrantes da expe- } \\
\text { dição/estudo (L). }\end{array}$ \\
\hline
\end{tabular}

Fonte: Elaborado pelas autoras (2013).

Nota: (L) linguagem natural. 
Quadro 2. Porção aparente do território.

\begin{tabular}{|c|c|c|}
\hline Categoria e subcategorias & Conceituação & Termos \\
\hline Porção aparente do Território & $\begin{array}{l}\text { O território, que vem a ser a base geográfica do Estado (Ferreira, [197-]), } \\
\text { reflete-se em suas formas naturais, tais como relevo, vegetação, clima e } \\
\text { fixidez no espaço (Cruz, 2002). }\end{array}$ & $\begin{array}{l}\text { Território, Relevo, Vegetação, } \\
\text { Clima, Espaço (L). }\end{array}$ \\
\hline Regiões & $\begin{array}{l}\text { Áreas individualizadas identificadas por suas características físicas, humana } \\
\text { e econômica que apresentam paisagem diferenciada (Guerra, 1972). }\end{array}$ & Brasil, Nordeste; Brasil, Sul (LC). \\
\hline Estado & $\begin{array}{l}\text { Agrupamento de unidades federadas ligadas por ocorrências geográficas } \\
\text { dominantes e características comuns, formando conjuntos peculiares e } \\
\text { preponderantes (Resolução no 72, de } 14 \text { de julho de 1941, da Assembleia } \\
\text { Geral do Conselho Nacional de Geografia (CNG) (Conselho Nacional de } \\
\text { Geografia, 1951-1952). }\end{array}$ & $\begin{array}{l}\text { Estados das Regiões Nordeste } \\
\text { (Maranhão, Piauí, Ceará, Rio } \\
\text { Grande do Norte, Paraíba, Per- } \\
\text { nambuco e Alagoas) e Sul (São } \\
\text { Paulo, Paraná, Santa Catarina e } \\
\text { Rio Grande do Sul) (L/LC). }\end{array}$ \\
\hline Município & Circunscrição administrativa autônoma do Estado (Ferreira, [197-]. & $\begin{array}{l}\text { Documentação Territorial do } \\
\text { Brasil (Municípios das regiões } \\
\text { Nordeste e Sul). Ex.: Nova Fáti- } \\
\text { ma (PR); Nova Fátima (BA). }\end{array}$ \\
\hline $\begin{array}{l}\text { Unidade com categoria } \\
\text { administrativa }\end{array}$ & $\begin{array}{l}\text { Nomes próprios geográficos que representam unidades administrativas } \\
\text { (Maroun \& Neves, 1996). }\end{array}$ & $\begin{array}{l}\text { Distritos, vilas, povoados, pra- } \\
\text { ças, parques, etc. (L/LC). }\end{array}$ \\
\hline Relevo & $\begin{array}{l}\text { Diversidade de aspectos da superfície terrestre que compõem as formas } \\
\text { da paisagem física (Guerra, 1972). }\end{array}$ & $\begin{array}{l}\text { Chapadas (L); }(\mathrm{L}) \text {; Encostas }(\mathrm{L}) \text {; } \\
\text { Escarpas (L); Montanhas (L); } \\
\text { Planícies (L/LC); Planaltos (L); } \\
\text { Pediplanos (L); Serras (L); } \\
\text { Tabuleiros (L); Terraços (L/LC); } \\
\text { Vales (L/LC); Várzeas (L/LC). }\end{array}$ \\
\hline Vegetação & $\begin{array}{l}\text { Cobertura vegetal e florística do solo que individualiza uma região } \\
\text { (Guerra, 1972). }\end{array}$ & $\begin{array}{l}\text { Matas }(\mathrm{L}) \text {; Florestas }(\mathrm{L} / \mathrm{LC}) \text {; } \\
\text { Cerrados }(\mathrm{L} / \mathrm{LC}) \text {; Caatinga }(\mathrm{L} / \\
\mathrm{LC}) \text {; Babaçuais }(\mathrm{L}) \text {; Carnaubais } \\
(\mathrm{L}) \text {; Carnaubeira }(\mathrm{LC}) \text {. }\end{array}$ \\
\hline Climatologia & $\begin{array}{l}\text { Estudo dos climas do globo que explica certas formas de relevo e de } \\
\text { cujos fatores geomorfológicos individuais dependem as relações do } \\
\text { clima da paisagem respectiva (Guerra, 1972). }\end{array}$ & $\begin{array}{l}\text { Nordeste: Semiárido (Sertões); } \\
\text { Semiúmido (Serras); Úmido } \\
\text { (Litoral) (L). Sul: Subtropical } \\
\text { úmido. }\end{array}$ \\
\hline
\end{tabular}

Fonte: Elaborado pelas autoras (2013).

Nota: L: Linguagem natural; LC: Linguagem Controlada.

Biblioteca Nacional; e L (uso da linguagem natural), para aqueles retirados das legendas da própria fotografia ou da literatura mencionada (uso da linguagem livre). Com relação aos nomes de municípios os mesmos foram consultados na Documentação Territorial do Brasil sob a responsabilidade do IBGE.

\section{Comparação entre os procedimentos de análise e indexação das fotografias}

Objetivando identificar as lacunas que se apresentam na análise documentária aplicada às fotografias desse acervo, estabeleceu-se uma comparação entre a descrição e a análise feitas pelo sistema com a nova proposta. Optou-se por examinar e confrontar uma fotografia (Figura 1) selecionada do acervo que registra a Região Sul, precisamente o estado de Santa Catarina, município de Nova Trento. A seguir é apresentada a fotografia selecionada para fins comparativos. Primeiramente, verificou-se a descrição e análise disponibilizadas no Sistema. Em seguida, aplicou-se a nova proposta de matrizà paisagem selecionada, cujo objetivo é potencializar a indexação e a recuperação do conteúdo da imagem. 
Quadro 3. Configuração territorial.

\begin{tabular}{|c|c|c|}
\hline Categoria e subcategorias & Conceituação & Termos \\
\hline Configuração territorial & $\begin{array}{l}\text { Intervenções humanas que operam transformações do ambiente } \\
\text { as quais se verificam nos estudos e análises regionais. }\end{array}$ & $\begin{array}{l}\text { Intervenções humanas; Transforma- } \\
\text { ções ambientais; Análi-ses regionais (L). }\end{array}$ \\
\hline Imigrantes & $\begin{array}{l}\text { População não-ibérica que se estabeleceu no Brasil Meridional } \\
\text { contribuindo para os traços originais da paisagem (Waibel, 1949; } \\
\text { Geiger \& Vieira, 1962). }\end{array}$ & $\begin{array}{l}\text { Alemães; italianos; poloneses; japo- } \\
\text { neses; Russos (L/LC). }\end{array}$ \\
\hline População rural & $\begin{array}{l}\text { Pequenos proprietários rurais retirando da terra seu sustento } \\
\text { (Waibel, 1949; Meinicke, 1960). }\end{array}$ & $\begin{array}{l}\text { Camponeses }(L / L C) ; \text { Colonos }(L) ; \text { Serta- } \\
\text { nejos (L/LC). }\end{array}$ \\
\hline Atividades econômicas & $\begin{array}{l}\text { Economia de consumo baseada na agricultura familiar e pecuária } \\
\text { voltada para a autossuficiência (Câmara, 1948; Mascarenhas, } \\
\text { 1960). }\end{array}$ & $\begin{array}{l}\text { Agricultura: Viticultura (L); Fruticultura } \\
(\mathrm{L} / \mathrm{LC}) \text {; Extativismo vegetal (L/LC). } \\
\text { Pecuária (Criação de animais domés- } \\
\text { ticos): Gado (L/LC); Aves (L/LC); Coelho } \\
(\mathrm{L} / \mathrm{LC}) \text {; Ovelha (L/LC); Porco }(\mathrm{L}) \text {; Carneiro } \\
(\mathrm{L} / \mathrm{LC}) \text {. }\end{array}$ \\
\hline Unidade autônoma agrícola & $\begin{array}{l}\text { Local destinado à exploração agropecuária exercida em pequena } \\
\text { escala visando à autossuficiência (Prost, 1968). }\end{array}$ & Chácaras (L); Fazendas (L); Sítios (L/LC). \\
\hline $\begin{array}{l}\text { Unidade sem categoria } \\
\text { administrativa }\end{array}$ & $\begin{array}{l}\text { Nome próprio atribuído a propriedades privadas (Maroun \& } \\
\text { Neves, 1996). }\end{array}$ & Sítios, Fazendas (L). \\
\hline Áreas rurais & $\begin{array}{l}\text { Áreas visando à autossuficiência de acordo com o relevo (Cataldo, } \\
\text { 1962; Prost, 1968). }\end{array}$ & $\begin{array}{l}\text { Campos (L); Pastagens (L/LC); Lavouras } \\
(L / L C) \text {. }\end{array}$ \\
\hline Produtos agrícolas regionais & $\begin{array}{l}\text { Produtos do reino vegetal encontrados em estado nativo e } \\
\text { produtos do reino animal vinculados ao clima e aos solos (Prost, } \\
\text { 1968). }\end{array}$ & $\begin{array}{l}\text { Algodão; Arroz; Babaçu; Cacau; Car- } \\
\text { naúba; Coco; Cana-de-açúcar; Café; } \\
\text { Cera de carnaúba; Fumo; Mandioca; } \\
\text { Milho; Feijão; Uva; Madeira; Couros; } \\
\text { Peles (L/LC). }\end{array}$ \\
\hline Animais domésticos & $\begin{array}{l}\text { Animais criados em áreas pastoris ou em edificações rurais } \\
\text { visando atender necessidades e/ou atividades econômicas (Prost, } \\
\text { 1968). }\end{array}$ & $\begin{array}{l}\text { Aves; Asinino; Boi; Cavalo; Carneiro; } \\
\text { Coelho; Porco; Ovelha (L/LC). }\end{array}$ \\
\hline Trabalhadores rurais & $\begin{array}{l}\text { Pessoal fixado ao solo que desempenha atividades rurais e possui } \\
\text { conhecimentos que atendem às exigências da região onde vive } \\
\text { (Barros, 1949). }\end{array}$ & $\begin{array}{l}\text { Apanhadores }(\mathrm{L}) \text {; Bagaceiros }(\mathrm{L}) \text {; Car- } \\
\text { roceiros }(\mathrm{LC}) \text {; Cortadores }(\mathrm{L}) \text {; Carpin- } \\
\text { teiros }(\mathrm{L} / \mathrm{LC}) \text {; Ervateiros }(\mathrm{L}) \text {; Feitores de } \\
\text { cera }(\mathrm{L}) \text {; Lavradores }(\mathrm{L}) \text {; Prenseiros }(\mathrm{L}) \text {; } \\
\text { Trouxeiros }(\mathrm{L}) \text {; Vaqueiros }(\mathrm{L} / \mathrm{LC}) \text {. }\end{array}$ \\
\hline Instrumentos agrícolas & $\begin{array}{l}\text { Instrumentos movidos a motor ou não, empregados para pre- } \\
\text { parar o solo, plantar, cultivar, colher e transportar cargas (Smith, } \\
\text { 1947). }\end{array}$ & $\begin{array}{l}\text { Arados (L/LC); Carroças (4 rodas) (L/LC); } \\
\text { Carros de boi (2 rodas) (L); Caminhões } \\
(\mathrm{L} / \mathrm{LC}) ; \text { Ceifeiras (L/LC); Enxadas }(\mathrm{L}) ; \\
\text { Semeadeira ( } \mathrm{L} / \mathrm{LC}) ; \text { Adubadeira }(\mathrm{L} / \mathrm{LC}) ; \\
\text { Tratores (L/LC); Picapes (Veículo utilitá- } \\
\text { rio) (LC). }\end{array}$ \\
\hline Edificações rurais & $\begin{array}{l}\text { Construções destinadas ao armazenamento de produtos agrope- } \\
\text { cuários; abrigo e criação de animais domésticos que revelam a } \\
\text { influência cultural (Valverde, 1948). }\end{array}$ & $\begin{array}{l}\text { Estábulos (L/LC); Galpões (L); Paióis } \\
(\mathrm{L} / \mathrm{LC}) \text {; Potreiros }(\mathrm{L}) \text {; Serrarias }(\mathrm{L} / \mathrm{LC}) \text {. }\end{array}$ \\
\hline Edificações culturais & $\begin{array}{l}\text { Construções em alvenaria ou madeira tendo por finalidade aten- } \\
\text { der à população rural na aquisição da aprendizagem e cultos } \\
\text { religiosos loca-lizados no centro do aglomerado (Valverde, 1948). }\end{array}$ & $\begin{array}{l}\text { Capelas; Escolas; Igrejas (Edifícios) } \\
(\mathrm{L} / \mathrm{LC}) .\end{array}$ \\
\hline Habitação rural & $\begin{array}{l}\text { Construções em alvenaria ou madeira destinadas à moradia da } \\
\text { população rural possuindo área reduzida e limitada por cercas } \\
\text { (Valverde, 1948). }\end{array}$ & $\begin{array}{l}\text { Casas de colonos; Casas de madeira; } \\
\text { Casas de palha de babaçu (L); Casas de } \\
\text { fazenda ( }(L C) \text {. }\end{array}$ \\
\hline
\end{tabular}

Fonte: Elaborado pelas autoras (2013).

Nota: L: Linguagem natural; LC: Linguagem Controlada. 
Quadro 4. Paisagem típica (valor simbólico).

\begin{tabular}{|c|c|c|}
\hline Categoria e subcategorias & Conceituação & Termos \\
\hline Paisagem típica (valor simbólico) & $\begin{array}{l}\text { A memória social (Schama, 1996; Burke, 2004) está associada ao } \\
\text { meio físico redocumentando espaços relacionados à vida rural } \\
\text { que se desenrola naquelas regiões. }\end{array}$ & $\begin{array}{l}\text { Memória social; Meio físico e Paisagem; } \\
\text { Formas Naturais e Paisagem(L). }\end{array}$ \\
\hline Meio Físico (contexto geográfico) & $\begin{array}{l}\text { Conjunto de formas naturais na paisagem que se articula com a } \\
\text { percepção humana influenciando na visão de mundo (Schama, } \\
\text { 1996; Burke, 2004). }\end{array}$ & $\begin{array}{l}\text { Florestas }(\mathrm{L} / \mathrm{LC}) \text {; Matas }(\mathrm{L}) \text {; Caatinga }(\mathrm{L} / \\
\mathrm{LC}) \text {; Cerrados }(\mathrm{L} / \mathrm{LC}) \text {; Rios }(\mathrm{L} / \mathrm{LC} \text {; Rochas } \\
(\mathrm{L} / \mathrm{LC}) \text {. }\end{array}$ \\
\hline
\end{tabular}

Fonte: Elaborado pelas autoras (2013).

Nota: L: Linguagem natural; LC: Linguagem Controlada.

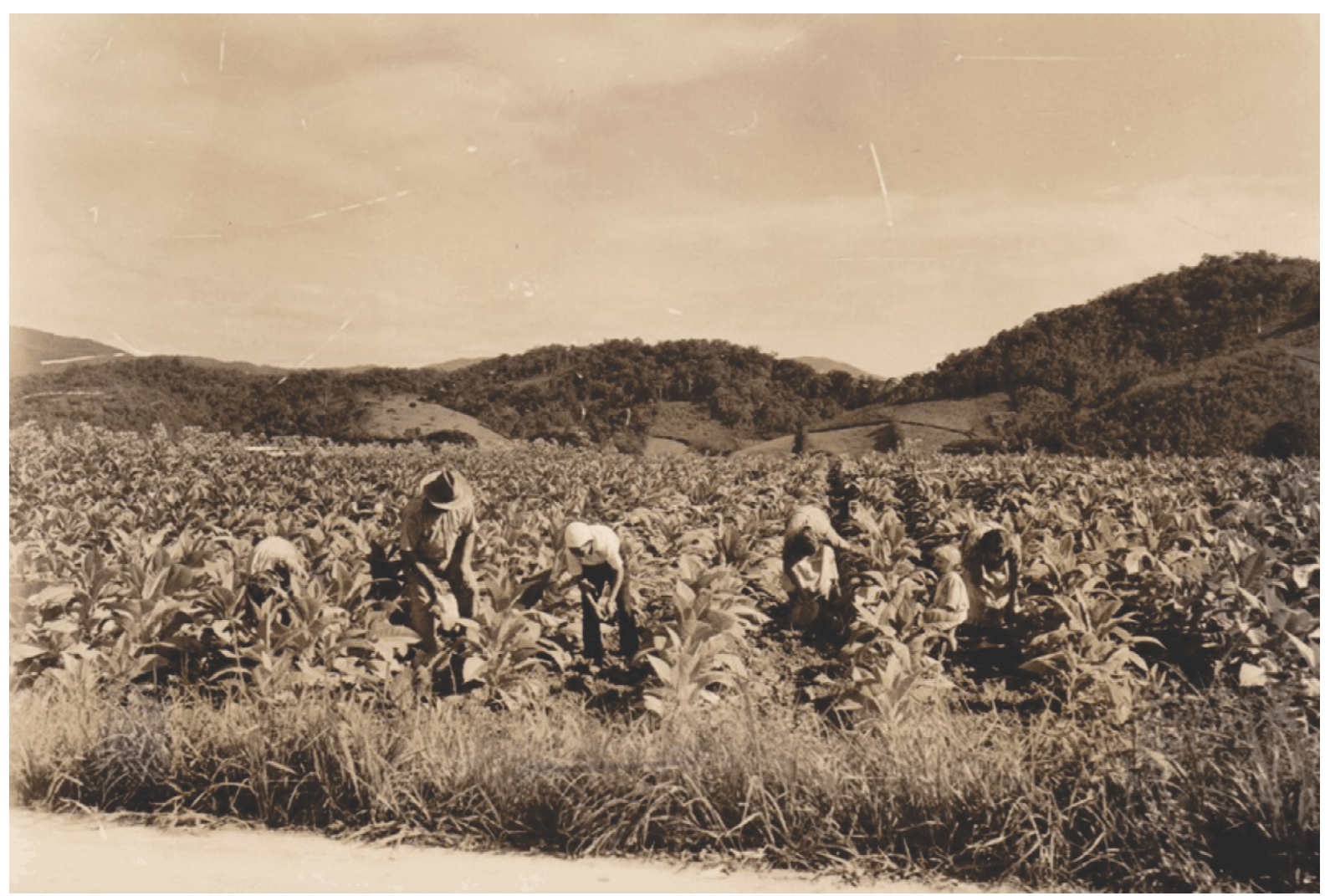

Figura 1. Família de colono italiano colhendo fumo: município de Nova Trento (SC) (1953).

Fonte: Romariz (1953).

\section{Descrição disponibilizada no Sistema Infobib:}

Autor: Romariz, Dora do Amarante; Somlo, Tomas/Título: Família de colono italiano colhendo fumo (SC)/Local: [S.I.]/Ano: 1953/Descrição física: 1 fot. : neg., p\&b/Série: Acervo dos trabalhos geográficos de campo/ Notas: Negativo 862.

Assuntos: Cultivos agrícolas; Fumo; Nova Trento (SC);
Pessoas; Relevo (Geografia); Santa Catarina; Vegetação e clima

\section{Nova proposta}

A) Contexto Histórico de Produção:

Ano da expedição/estudo: 1953; Objetivo(s): Mapa da vegetação original do estado de Santa Catarina 
(Fonte: Revista Brasileira de Geografia, 1953) / Estudo para o Atlas da Colonização do Sul do Brasil (Fonte: Revista Brasileira de Geografia, 1953); Integrantes: Geógrafo: Dora do Amarante Romariz; Fotógrafo: Tomas Somlo.

\section{B) Porção Aparente do Território:}

Região: Brasil, Sul; Estado: Santa Catarina; Município: Nova Trento (SC); Unidade com Categoria Administrativa: Não se aplica; Relevo: Montanhas; Vegetação: Matas; Florestas; Climatologia: Subtropical úmido.

\section{C) Configuração Territorial:}

Imigrantes: Italianos; População Rural: Camponeses; Colonos; Atividades Econômicas: Agricultura; Unidade Autônoma Agrícola: Sítio; Unidade sem Categoria Administrativa: Não se aplica; Áreas Rurais: Lavouras; Campos; Produtos Agrícolas Regionais: Fumo; Animais Domésticos: Não se aplica; Trabalhadores Rurais: Lavradores; Instrumentos Agrícolas: Não se aplica; Edificações Rurais: Não se aplica; Edificações Culturais: Não se aplica; Habitação Rural: Não se aplica.

\section{D) Paisagem Típica:}

Meio Físico: Matas; Florestas.

\section{Discussão}

Comparando-se ambas as representações da mesma fotografia, verificou-se que os assuntos são analisados com uma abordagem geral, sem especificar as categorias e as subcategorias que poderiam ser aplicadas a esses mesmos documentos no que diz respeito ao conteúdo das imagens analisadas. Desse modo, os resultados oferecidos pela matriz concebida respondem a critérios que devem nortear a representação documentária, através de parâmetros que assegurem os princípios da margem de segurança, o da coincidência e o da polirrepresentação (Cordeiro, 2000).

Pelo princípio da margem de segurança, a matriz modelada garante ao indexador identificar pontos de acesso que, relacionados ao documento, tornam-se indicadores constantes, visando diminuir a incerteza dos aspectos analisados na fotografia. A abrangência de pontos de acesso, expressa pelas vinte e uma categorias iden- tificadas na matriz, promove, entre diferentes grupos de usuários, pesquisadores de imagens, geógrafos, historiadores, arquivistas, bibliotecários e educadores, o acesso coletivo às informações contidas no acervo, que pela leitura do indexador poderá impulsionar a interação entre usuário e documento.

Na concepção da matriz modelada, considerando a dimensão histórica e seu contexto de produção, juntamente aos preceitos das áreas de Ciência da Informação e Biblioteconomia, acredita-se estar colocando em prática o princípio da polirrepresentação. Isso acontece quando se ampliam as categorias e as subcategorias de análise, possibilitando proporcionar a múltiplos grupos de usuários pontos de acesso para diferentes perguntas ao sistema. Ao analisar as particularidades que as imagens oferecem expandiu-se, também, sua relevância que através de distintas abordagens confirmam o alto grau de interdisciplinaridade das fotografias do acervo, colaborando para que um número maior de usuários seja atendido em seus questionamentos em diferentes níveis, conforme pondera Cordeiro (2000). Em síntese, tendo como base os princípios citados, percebeu-se que por meio da testagem pode ser possível alcançar um padrão de segurança que influi nos resultados para recuperação desses conjuntos de documentos quando comparados à análise anterior.

\section{Conclusão}

O estudo das fotografias a partir das paisagens e do espaço condizentes à vida rural no contexto da época, resultou na proposta de criação de novas categorias analíticas que foram aplicadas na indexação e recuperação das imagens do acervo. Isso permitiu maior visibilidade da imagem fotográfica captada nas décadas dos anos 1940 a 1960 pelos geógrafos expedicionistas do IBGE. As respostas obtidas na categorização das classes mostraram a importância do arcabouço teórico quando do levantamento bibliográfico seletivo nas áreas de Arquivologia, Biblioteconomia, Ciência da Informação, Geografia e História, pois evidenciaram subsídios que permitiram identificar e levantar as características representativas da paisagem que integram a matriz proposta. 
Depois de composta a matriz, sua verificação, quando aplicada aos conjuntos de documentos selecionados, explicitou quão necessário se faz para a análise indexadora assegurar princípios convergentes à margem de segurança dos aspectos alvo. Isso porque potencializam o grau informativo dos documentos, em especial os desse acervo, que, perante diferentes pontos de acesso, promovem a interação conferida pela sua interdisciplinaridade no conjunto total de documentos, os usuários de diferentes segmentos do sistema, alcançando, também, futuros usuários (pesquisadores em imagem, geógrafos, historiadores, educadores, alunos de ensino médio e graduação, entre outros).
Assim, a pluralidade de pontos de acesso sugerida na matriz funciona, pode-se dizer, como um vetor que confere ao Arquivo Fotográfico Ilustrativo dos Trabalhos Geográficos de Campo do IBGE o"certificado de presença" da fotografia, atestando sua condição de importante fonte de informação visual para a pesquisa no cenário da memória social.

\section{Colaboradores}

Todos os autores contribuíram na concepção e desenho do estudo, análise de dados e redação final.

\section{Referências}

Alves, F.D. Os métodos da geografia agrária clássica: contribuição para história do pensamento geográfico. In: Encontro Nacional de Geografia Agrária, 19., 2009, São Paulo. Anais eletrônicos... São Paulo: USP, 2009. Disponível em: <http://www. geografia.fflch.usp.br/inferior/laboratorios/agraria/Anais\%20 XIXENGA/artigos/Alves_FD.pdf>. Acesso em: 13 maio 2013.

Barros, L.F. Fotografias aéreas. Boletim Geográfico [do IBGE], v.22, n.178, p.109, 1964.

Barros, S. Raízes tropicais do Nordeste. Revista Brasileira de Geografia, v.11, n.3, p.409-426, 1949.

Bertrand, G. Paisagem e geografia física global: esboço metodológico. São Paulo: USP, 1972. (Caderno de Ciências da Terra, 13)

Blanc-Pamard, C.; Raison, J.P. Paisagem. In:Enciclopédia Einaudi. Porto: Imprensa Nacional, 1986. v.8. p.262-289.

Burke, P. Testemunha ocular: história e imagem. Bauru: Edusc, 2004.

Câmara, L. Estrangeiros em Santa Catarina. Revista Brasileira de Geografia, v.10, n.2, p.211-254, 1948.

Cataldo, D.M. Aspectos humanos e econômicos do Sul. In: Conselho Nacional de Geografia (Org.). Paisagens do Brasil. 2.ed. Rio de Janeiro: IBGE, 1962. p.251-259.

Conselho Nacional de Geografia (Brasil). Resoluções da assembleia geral: n.1-365, 1934-1954. Rio de Janeiro: IBGE, 1951-1952.

Cordeiro, R.I.N. Informação e movimento: uma ciência da arte fílmica. Rio de Janeiro: Madgráfica, 2000.

Cordeiro, R.I.N. O movimento, a natureza e a produção de sentido no documento imagético: uma perspectiva do seu potencial informativo para análise documentária. In: Serafim, J. F.; Toutain, L.B.; Geffroy, Y. (Org.). Perspectivas em informação visual: cultura, percepção e representação. Salvador: EdUFBA, 2010. p.107-122.
Cruz, R.C.A. As paisagens artificiais criadas pelo turismo. In: Yázigi, E. (Org.). Turismo e paisagem. São Paulo: Contexto, 2002. p.107-119.

Enser, P.G.B. Information seeking and retrieval. Annual Review of Information Science and Technology Science and Technology, v.42, n.1, p.1-42, 2009.

Ferreira, A.B.H. Novo dicionário da língua portuguesa. Rio de Janeiro: Nova Fronteira, [197-].

Geiger, P.P.; Vieira, M. C. Aspectos físicos do Sul. In: Conselho Nacional de Geografia (Org.). Paisagens do Brasil. 2.ed. Rio de Janeiro: IBGE, 1962. p.229-244.

Guerra, A.T. Dicionário geológico-geomorfológico. 4.ed. Rio de Janeiro: IBGE, 1972.

Guimarães, J.A.C. Abordagens Teóricas de Tratamento Temático da Informação (TTI): catalogação de assunto, indexação e análise documental. Ibersid: revista de sistemas de información y documentación, v.3, p.105-117, 2009. Disponible en: <http://ibersid.eu/ojs/index.php/ ibersid/ article/viewFile/3730/3491 >. Acceso en: 10 dic. 2014.

Instituto Brasileiro de Geografia e Estatística. Relatório do presidente do IBGE, apresentado ao sr. presidente da República: Conselho Nacional de Geográfia, 1939. Boletim Geográfico, Rio de Janeiro, v.4, n.45, p.1173, 1946. Disponível em: <http://biblioteca.ibge.gov.br/visualizacao/periodicos/ 19/bg_1946_v4_n45_dez.pdf>. Acesso em: 13 maio 2013.

Lancaster, F. W. Indexação e resumos: teoria e prática. 2.ed. Brasília: Briquet de Lemos, 2004.

Lima, G.A.B.O. Modelos de categorização: apresentando o modelo clássico e o modelo de protótipos. Perspectivas em Ciência da Informação, v.15, n.2, p.108-122, 2010.

Maroun, M.C.S.B.; Neves, M. L.T. P. Nomes geográficos: normas para indexação. Rio de Janeiro: IBGE, 1996.

Mascarenhas, E. Nordeste. In: Guerra, A.T.; Carvalho, E. (Org.). Geografia do Brasil: roteiro de uma viagem. Rio de Janeiro: IBGE, 1960. p.57-104. Disponível em: <http://biblioteca. 
ibge.gov.br/index.php/biblioteca-catalogo?view=detalhes \&id=213762>. Acesso em: 10 jan. 2012.

Meinicke, N.P. A colonização alemã e italiana no Rio Grande do Sul. In: Guerra, A.T.; Carvalho, E. (Org.). Geografia do Brasil: roteiro de uma viagem. Rio de Janeiro: IBGE, 1960. p.236-240. Disponível em: <http://biblioteca.ibge.gov.br/index.php/ biblioteca-catalogo?view=detalhes\&id=213762>. Acesso em: 10 jan. 2012.

Prost, G. O Cariri semiárido transformado pela agave. Revista Brasileira de Geografia, v.30, n.2, p.21-55, 1968.

Raper, J. Geographic information science. Annual Review of Information Science and Technology, v.43, n.1, p.1-117, 2011.

Romariz, D.A. Mapa da vegetação original do Estado do Paraná. Revista Brasileira de Geografia, v.15, n.4, p.597-612, 1953.
Ruellan, F. Orientação científica dos métodos de pesquisa geográfica. Revista Brasileira de Geografia, v.5, n.1, p.51-60, 1943.

Santos, M. A natureza do espaço: técnica e tempo: razão e emoção. 4.ed. São Paulo: EdUSP, 2009.

Schama, S. Paisagem e memória. São Paulo: Companhia das Letras, 1996.

Smith, T.L. Sistemas agrícolas. Revista Brasileira de Geografia, v.9, n.2, p.159-184, 1947

Valverde, O. Excursão à região colonial antiga do Rio Grande do Sul. Revista Brasileira de Geografia, v.10, n.4, p.477-534, 1948.

Waibel, L. Princípios da colonização europeia no Sul do Brasil. Revista Brasileira de Geografia, v.11, n.2, p.159-222, 1949. 

